\title{
Strategies to Handle Increased Demand in the COVID- 19 Crisis a Corona Telephone Hotline and a Web- based Self-triage System
}

Theo Walther Jensen ( $\nabla$ theo.walther.jensen.01@regionh.dk)

Copenhagen Emergency Medical Services https://orcid.org/0000-0001-6468-0146

Mathias Geldermann Holgersen

Kobenhavns Universitet Sundhedsvidenskabelige Fakultet

Mads Seit Jespersen

Kobenhavns Universitet Sundhedsvidenskabelige Fakultet

Stig Nikolaj Blomberg

Copenhagen Emergency Medical Services

Fredrik Folke

Copenhagen Emergency Medical Services

Freddy Knudsen Lippert

Copenhagen Emergency Medical Services

Helle Collatz Christensen

Copenhagen Emergency Medical Services

Research article

Keywords:

Posted Date: June 1st, 2020

DOI: https://doi.org/10.21203/rs.3.rs-30013/v1

License: (1) This work is licensed under a Creative Commons Attribution 4.0 International License. Read Full License 


\section{Abstract}

\section{Background}

In emergencies, such as the COVID-19 pandemic, there is an increased need for contact withemergency medical services (EMS), and call volume might surpass capacity. Thus, the Copenhagen EMS in Denmark implemented a separate coronavirus hotline followed by a web-based self-triage system to reduce nonemergency call volume. The aim of this paper is to present the two measures implemented to handle the increased call volume to the Copenhagen EMSfromthose with mild or no relevant COVID-19 symptoms.

\section{Methods}

This is a cross sectional observational study monitoring call volume in the first month of the COVID-19 pandemic in accumulated callnumbers, compared to the equivalent numbers during one month from the year before (2019). A coronavirus hotline and web-based self-triage system arepresented in absolute numbers of users.

\section{Results}

In the first month of the COVID-19 pandemic in Copenhagen, emergency medical dispatch centers were extensively overloaded with more than 10.800 calls, resulting in significantly prolonged queue time (mean time in minutes:12:02; Cl: 11:55-12:09)) compared to 2019 (mean time in minutes02:23; Cl: 02:22-02:25) and thereby limiting access to emergency assistance and triage for citizens. The introduction of the coronavirus hotline showed reduced call volume and queue time to the EMS. The web-based self-triage system was used more than 107.000 times. However, no correlation between call volume and the use of a web-based self-triage systemwas observed.

\section{Conclusions}

Creating a coronavirus hotlinestaffed by healthcare personnelseemed to have an impact on call volume and potentially relieved the strain in resources, while the web-based self-triage system was widely used and could be further developed to reach itsfull potential. Other EMS organizations can implement these measures to enhance capacity in a future epidemic.

\section{Method}

This investigation is a cross sectional observational study examining the effect of implementing a coronavirus hotline and WBSTS on EMS call volume.

\section{Setting}


The Capital Region of Denmark, Copenhagen, has 1.8 million inhabitants served by the Copenhagen EMS. The Copenhagen EMS is an integrated health care service comprised of an emergency medical dispatch call center, ambulance service and physician- and paramedic-staffed mobile critical care units. The Copenhagen EMS is accessed through two main numbers, namely, 1-1-2 (the European emergency number) for life-threatening emergencies and 1813 (medical helpline) for all other urgent medical issues, including access to emergency departments. Both lines manage and triage all urgent hospital admissions and as gateway to all hospital contact central components of the health care system. The 1813 medical helpline receives approximately 1,800 calls on weekdays and 3,500 calls daily on weekends. Each caller is triaged to either advice, admission to the emergency department (including booking a time slot), direct hospitalization, dispatch of ambulance response or home-visit by a physician.

\section{The Coronavirus hotline}

The hotline was launched on March 4, 2020, as a separate queue system and was established as a standalone call center on March 9. The hotline was staffed by 5-18 persons at peak, all with a healthcare-related educational background (e.g., nurses, medical students, medical doctors). The staff was instructed to follow a protocol resulting in the algorithmic placement of responses (Fig. 1). The caller could eventually be given advice on actions or self-isolation or be directed to the emergency EMS line for triage.

All callers who contacted the 1813 medical helpline were presented with the option to either go to the coronavirus hotline if they were calling concerning COVID-19 or continue to the normal EMS if their call concerned other emergent medical issues (Fig. 1). All calls regarding life-threatening emergencies were directed to call the 1-1-2 emergency line.

Insert the following here: Fig. 1. Flowchart for the coronavirus hotline

\section{Development of the Web-based Self-Triage System}

The development of the WBSTS was initiated on March 12, and the system was ready to launch only three days later. A simple algorithm based on the triage of potential COVID-19-infected patients (Fig. 2) was designed and implemented as an online web application for inclusion on the already-established Copenhagen EMS webpage and initiated on March 15.

Insert the following here: Fig. 2. Flowchart for the initial web-based self-triage system

Dissemination of the coronavirus hotline and the WBSTS

Awareness of the WBSTS and the coronavirus hotline was initially disseminated to the public through a press release by the Copenhagen EMS, the Capital Region and the websites and social media channels (Twitter ${ }^{\circledR}$ and Facebook ${ }^{\circledR}$ ) of hospitals in the region.

\section{Data collection}

Data were collected from February 26, 2020, to March 27, 2020, for all calls to the 1-1-2 emergency line and 1813 medical helpline, and for the WBSTS. The data was stratified by the access number used, i.e., the 1-1-2 emergency line, the 1813 medical line and the coronavirus hotline. Data regarding caller demographics and 
referrals were obtained by the Copenhagen EMS dispatch system. All data were obtained via the Copenhagen EMS line audits

\section{Statistics}

Descriptive analyses were performed. Absolute numbers and percentages for variables were reported. Comparative analyses were performed using chi-square tests and Student's t-tests. A calculation was performed using ANOVA for the comparison analysis. All analyses were performed using SAS Statistical Enterprise Software, version 7.11.

\section{Ethics}

We followed the General Data Protection Regulation and registered the study with the Danish Data Protection Agency (journal number P-2020-343). The study was approved by the Danish Patient Safety Authority (journal number 31-1521-267). The Research Ethics Committee in the Capital Region of Denmark waived the need for ethical approval (journal number 20026743).

\section{Results}

On February 27, 2020, Denmark had the first confirmed case of COVID-19 (indicator patient). The Danish health care authorities observed a steep rise in the number of confirmed cases, with a daily doubling in the number of cases from March 8-11. On March 12, the strategy officially changed from containment and suppression to mitigation and preparation. On March 14, the first official mortality due to COVID-19 was confirmed.

\section{The EMS call volume}

Overall calls volume for Copenhagen EMS was increased by $24 \%$ in the period, mostly to the coronavirus hotline. An increase in the EMS call volume for 1813 calls (excluding the coronavirus hotline) from the first confirmed case in Denmark on February 27, 2020, until one month later March 27, 2020, was not observed compared to the same period in 2019.

The EMS 112 emergency line received 8,870 calls in 2020 compared to 8,494 in 2019, and the 1813 medical helpline received 84,317 in 2020 compared to 84,176 in 2019 (Table 1) from February 26 until one month after. There was a difference in the age of the callers (a mean of 53.0 years in 2020 and a mean of 53.6 years in 2019). Similarly, minor but not clinically relevant differences can be observed for the 1813 medical helpline (Table 1). There was no apparent difference in the relative distribution of call volume by day or day of the week (Table 1). 
Table 1

Demographics of EMS calls from February 27 to March 27, 2020

\begin{tabular}{|c|c|c|c|c|c|c|c|}
\hline & $1-1-2$ & & \multirow[t]{3}{*}{$\mathbf{P}$} & \multicolumn{2}{|c|}{1813} & \multirow[t]{2}{*}{$P$} & \multirow{3}{*}{ 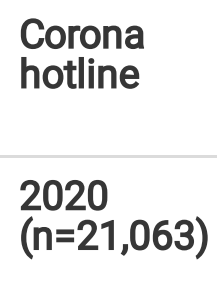 } \\
\hline & \multicolumn{2}{|c|}{ Emergency line } & & \multicolumn{2}{|c|}{ Medical helpline } & & \\
\hline & $\begin{array}{l}2019 \\
(n=8,494)\end{array}$ & $\begin{array}{l}2020 \\
(n=8,870)\end{array}$ & & $\begin{array}{l}2019 \\
(n=84,176)\end{array}$ & $\begin{array}{l}2020 \\
(n=84,317)\end{array}$ & $\begin{array}{l}2019 \\
\text { vs } \\
2020\end{array}$ & \\
\hline $\begin{array}{l}\text { Mean age, } \\
\text { years }\end{array}$ & & & \multirow[t]{2}{*}{$<.0001$} & \multirow{2}{*}{$\begin{array}{l}32.7(32.6- \\
32.9)\end{array}$} & \multirow[t]{2}{*}{$\begin{array}{l}33.7(33.5- \\
33.9)\end{array}$} & \multirow[t]{2}{*}{$<.0001$} & \multirow{2}{*}{$\begin{array}{l}33.8(33.6- \\
34.0)\end{array}$} \\
\hline$(95 \% \mathrm{Cl})$ & $\begin{array}{l}(53.0- \\
54.2)\end{array}$ & $\begin{array}{l}(52.4- \\
53.6)\end{array}$ & & & & & \\
\hline $\begin{array}{l}\text { Male }(\mathrm{n} \\
(\%))^{*}\end{array}$ & $\begin{array}{l}3,798 \\
(51.5)\end{array}$ & $\begin{array}{l}4,082 \\
(51.8)\end{array}$ & .5149 & $\begin{array}{l}38,432 \\
(46.4)\end{array}$ & $\begin{array}{l}39,922 \\
(46.5)\end{array}$ & .5100 & $\begin{array}{l}8,824 \\
(49.7)\end{array}$ \\
\hline \multicolumn{8}{|l|}{ Time of day. } \\
\hline 07:00-14:59 & $\begin{array}{l}3,526 \\
(41.5)\end{array}$ & $\begin{array}{l}3,439 \\
(38.7)\end{array}$ & .0002 & $\begin{array}{l}28,231 \\
(33.5)\end{array}$ & $\begin{array}{l}28,182 \\
(32.4)\end{array}$ & .0052 & $\begin{array}{l}7,011 \\
(33.3)\end{array}$ \\
\hline 15:00-22:59 & $\begin{array}{l}3,304 \\
(38.9)\end{array}$ & $\begin{array}{l}3,666 \\
(41.3)\end{array}$ & .0011 & $\begin{array}{l}44,913 \\
(53.3)\end{array}$ & $\begin{array}{l}46,183 \\
(53.0)\end{array}$ & .0102 & $\begin{array}{l}11,739 \\
(55.7)\end{array}$ \\
\hline 23:00-06:59 & $\begin{array}{l}1,664 \\
(19.6)\end{array}$ & $\begin{array}{l}1,765 \\
(19.9)\end{array}$ & .9181 & $\begin{array}{l}11,138 \\
(13.2)\end{array}$ & $\begin{array}{l}12,697 \\
(14.6)\end{array}$ & $<.0001$ & $\begin{array}{l}2,313 \\
(11.0)\end{array}$ \\
\hline \multicolumn{8}{|l|}{ Day of week } \\
\hline Weekdays & $\begin{array}{l}6,193 \\
(72.9)\end{array}$ & $\begin{array}{l}6,277 \\
(70.8)\end{array}$ & $<.0001$ & $\begin{array}{l}51,712 \\
(61.4)\end{array}$ & $\begin{array}{l}55,031 \\
(63.2)\end{array}$ & $<.0001$ & $\begin{array}{l}15,113 \\
(71.8)\end{array}$ \\
\hline Weekends & $\begin{array}{l}2,301 \\
(27.1)\end{array}$ & $\begin{array}{l}2,593 \\
(29.2)\end{array}$ & $<.0001$ & $\begin{array}{l}32,570 \\
(38.6)\end{array}$ & $\begin{array}{l}32,031 \\
(36.8)\end{array}$ & $<.0001$ & $\begin{array}{l}5,950 \\
(28.2)\end{array}$ \\
\hline $\begin{array}{l}\text { Mean queue } \\
\text { time, }\end{array}$ & $\begin{array}{l}00: 05 \\
(00: 05- \\
00: 05)\end{array}$ & $\begin{array}{l}00: 05 \\
(00: 05- \\
00: 05)\end{array}$ & .6605 & $\begin{array}{l}02: 23 \\
(02: 22- \\
02: 25)\end{array}$ & $\begin{array}{l}12: 02 \\
(11: 55- \\
12: 09)\end{array}$ & $<.0001$ & $\begin{array}{l}13: 46 \\
(13: 29- \\
14: 02)\end{array}$ \\
\hline \multicolumn{8}{|l|}{$\begin{array}{l}95 \% \mathrm{Cl} \\
\text { [mm:ss] }\end{array}$} \\
\hline $\begin{array}{l}\text { Mean talk } \\
\text { time, 95\% } \mathrm{Cl} \\
\text { [mm:ss] }\end{array}$ & $\begin{array}{l}03: 20 \\
(03: 18- \\
03: 22)\end{array}$ & $\begin{array}{l}03: 40 \\
\text { (03:37- } \\
03: 42)\end{array}$ & $<.0001$ & $\begin{array}{l}03: 58 \\
(03: 57- \\
03: 59)\end{array}$ & $\begin{array}{l}04: 33(04: 32- \\
04: 34)\end{array}$ & $<.0001$ & $\begin{array}{l}03: 39 \\
(03: 37- \\
03: 42)\end{array}$ \\
\hline \multicolumn{8}{|l|}{ Response } \\
\hline $\begin{array}{l}\text { Emergency, } \\
\text { lights and } \\
\text { sirens }\end{array}$ & $\begin{array}{l}6,517 \\
(78.4)\end{array}$ & $\begin{array}{l}6,279 \\
(73.3)\end{array}$ & $<.0001$ & $3,526(4.2)$ & 3,066 (3.6) & $<.0001$ & $79(0.4)$ \\
\hline $\begin{array}{l}\text { Emergency, } \\
\text { not } \\
\text { transported }\end{array}$ & $\begin{array}{l}1,487 \\
(17.9)\end{array}$ & $\begin{array}{l}1,953 \\
(22.8)\end{array}$ & $<.0001$ & $361(0.4)$ & $297(0.4)$ & .0124 & $6(0.0)$ \\
\hline $\begin{array}{l}\text { Self- } \\
\text { care/GP** }\end{array}$ & $28(0.3)$ & $42(0.5)$ & .1509 & $37,329(44.3)$ & $\begin{array}{l}48,827 \\
(58.0)\end{array}$ & $<.0001$ & $\begin{array}{l}14,387 \\
(94.3)\end{array}$ \\
\hline
\end{tabular}




\begin{tabular}{|llllllll|}
\hline $\begin{array}{l}\text { Referred to } \\
\text { ED }\end{array}$ & $253(3.0)$ & $254(3.0)$ & .6850 & $\begin{array}{l}28,973 \\
(34.4)\end{array}$ & $\begin{array}{l}18,110 \\
(21.5)\end{array}$ & $<.0001$ & $335(1.6)$ \\
\hline $\begin{array}{l}\text { Hospitalized } \\
25(0.3)\end{array}$ & $42(0.5)$ & .0659 & $6,393(7.6)$ & $6,805(8.1)$ & $<.0001$ & $306(1.5)$ \\
\hline $\begin{array}{l}* \\
\text { Of contacts with known gender } \\
\text { ** Those who were not referred to the hotline are assumed to have concluded with self-care }\end{array}$ & \\
\hline
\end{tabular}

However, since the introduction of the coronavirus hotline on March 4, 2020, a large number of calls to the EMS were forwarded to the specific coronavirus hotline. The coronavirus hotline received a total call volume of 21,063 calls in this period (Table 1 ) and had mean queue times of 13 minutes and 46 seconds (Table 1 ).

Insert the following here: Table 1. Demographics of EMS calls from February 27 to March 27, 2020

The call volume on the coronavirus hotline peaked on March 12, with approximately 2,100 calls in one day. Furthermore, 4,409 (20.9\%) of the calls to the coronavirus hotline were redirected to the EMS 1813 medical helpline; these calls were to be further assessed and triaged by a physician.

Hence, in total, a significant $(P<0.001)$ increase in the total EMS call volume was observed, most extensively from March 2-15 but was mitigated by the implementation of to the coronavirus hotline (Fig. 3). After day 19 (March 15), a minor decrease in total call volume was witnessed on both the 1813 medical helpline and the specific coronavirus hotline (Fig. 3).

Insert the following here: Fig. 3. Accumulated call volumes and web-based self-triage system use

\section{EMS queue time}

Although call volume is seemingly not substantially higher once the capacity is overloaded, the EMS queue time is the first marker and will rise steeply. The limited capacity of the EMS 1813 medical helpline is seen to be significantly overloaded in this period, with significantly higher queue time than in 2019. In 2020, the mean queue time was 12 minutes and 2 seconds (Cl: 11:55 - 12:09), which is significantly $(P<0.001)$ higher than the two minutes and 23 seconds (Cl: 02:22 - 02:25) observed in 2019 (Table 1). Several periods with a maximum queue time of up to 2 hours was noted in the very peak of the corona burden prior to implementation of the coronavirus hotline.

Several peaks in queue time are notable on the EMS 1813 medical helpline, most notably on March 1, 8-9, 11-12 and 15 (Day 4,11-12, $14-5$ and18 in Fig. 4). The calls forwarded to the coronavirus hotline had a similar peak pattern after the implementation, except for the initial peak on March 1 prior to implementation (Fig. 4). The increase in queue time is due to not only an increase in call volume but also an increase in time for call handling (conversations are longer by approximately 1 minute).

Several events coincide with peaks in queue time, notably a slow peak in queue time in the days after the announcement of the first confirmed patient (see Fig. 4).

Insert the following here: Fig. 4. Queues for EMS lines and key events around the Danish COVID-19 impact Use of the WBSTS 
The WBSTS was implemented on March 15 and was included on the Copenhagen EMS webpage. In the first month, the WBSTS was used 107,894 times. A total of $92.2 \%$ of users completed all questions on the WBSTS, and $14.6 \%$ marked that they had respiratory distress (Table 2 ).

Table 2

Demographics of web-based self-triage system users

\begin{tabular}{|c|c|}
\hline Users (n) & 107,894 \\
\hline Age (median, IQR) & $42(31-54)$ \\
\hline \multicolumn{2}{|l|}{$\operatorname{Sex}, n(\%)$} \\
\hline Male & $10,117(40.7)$ \\
\hline Female & $14,766(59.3)$ \\
\hline Gender missing & 83,011 \\
\hline \multicolumn{2}{|l|}{ Time of day, $n(\%)$} \\
\hline 07:00-15:00 & $34,971(32.4)$ \\
\hline 15:00-23:00 & $61,627(57.1)$ \\
\hline 23:00-07:00 & $11,296(10.5)$ \\
\hline \multicolumn{2}{|l|}{ Weekday/weekend, n (\%) } \\
\hline Weekday & $66,935(62.0)$ \\
\hline Weekend & $40,959(38.0)$ \\
\hline \multicolumn{2}{|l|}{ Zip code (within the capital region), $n$ (\%) } \\
\hline Copenhagen & $11,952(49.6)$ \\
\hline Other & $12,169(50.4)$ \\
\hline \multicolumn{2}{|l|}{ Outcomes } \\
\hline Completed webtriage, $\mathrm{n}$ & 88,254 \\
\hline Initially reported pain and breathing difficulty, $n$ (\%) & $14,494(16.4)$ \\
\hline \multicolumn{2}{|l|}{ Responses, $n(\%)$} \\
\hline Call 1813 or GP & $35,956(40.7)$ \\
\hline Advised to self-isolate & $31,1-1-2(35.3)$ \\
\hline Not COVID-19 & $21,186(24.0)$ \\
\hline
\end{tabular}

A total of 24,883 users provided information and feedback for the system. Among the users agreeing to provide feedback, $80 \%$ found the system satisfactory, and $20 \%$ did not. The median age for users was 42 (IQR 31-54), with more female users (59\%). The WBSTS had more users in the daytime than at night. Of the three possible types of advice that could be offered, the WBSTS advised $24.0 \%(21,186$ calls) of users that they had 
reported symptoms of COVID-19, 35.3\% (31,1-1-2 calls) of users were advised to self-isolate, and $40.7 \%$ $(35,956$ calls) were advised to call the EMS and coronavirus hotline. No correlation between EMS call volume and use of the WBSTS could be documented.

Insert the following here: Table 2. Demographics of web-based self-triage system users

\section{Discussion}

\section{Main results}

This study found increasing call volume to the EMS during the beginning of the national COVID-19 pandemic. The queue time for both the 1813 medical helpline and the designated coronavirus hotline increased markedly during the first month of the impact of COVID-19 in Denmark to a mean of 12 minutes and 2 seconds in 2020, compared to an average of 2 minutes and 23 seconds in 2019. However, the impact was drastically reduced using a specific healthcare-staffed coronavirus hotline to forward all calls regarding the ongoing pandemic. In peak periods, the coronavirus hotline had a call volume that was similar to that of the EMS 1813 medical helpline and thus relieved the burden; the 1813 call volume returned to operating capacity after the burden was cut almost in half.

\section{Using a target healthcare-staffed hotline to relieve the EMS burden}

A 2009 nurse-staffed and American-based flu hotline created by the Centers for Disease Control (CDC) had the same aim of reducing call volume to the EMS [13]. One of the unresolved questions in the publication was whether the alternative call lines played a prominent role in a pandemic response to meet patients' needs and reduce the surge in healthcare facilities [13]. In Copenhagen, the coronavirus hotline managed almost the same number of calls as the EMS in the peak of the surge around March 11. Without the coronavirus hotline, the EMS would have been overwhelmed with an extensive line queue and, consequently, potential missed calls and delayed EMS or hospital responses, possibly leading to psychological barriers that cause callers to avoid contact.

\section{Web-based self-triage}

Another measure to reduce the strain on the EMS that differs from the CDC flu line was the establishment of the WBSTS. The WBSTS was widely used with more than 107,000 users from its launch until March 27. However, no apparent effect on call volume is indicated or documented. Users were mainly younger adults (median 44 years, IQR 31-54 years). The WBSTS was limited in interaction, and as expected, not all symptoms were presented; consequently, some potentially infected persons could have been missed [1, 1718]. The authors find that the WBSTS might run the risk of being too simple to be useful for some users (20\%). Furthermore, without revisions, some citizens might not trust the answers due to the simplicity and rigidity of the first version. For subsequent updates and revisions, the authors find it relevant to examine user engagement [19]. However, the central merit of a user WBSTS is that it can be developed and implemented in a matter of days to provide instant relief for EMS lines and offer relevant advice to citizens who are not in need of triage or healthcare advice beyond self-isolation or a test of symptoms. We found that $85.4 \%$ of WBSTS 
entries presented with mild or no relevant symptoms, and a proportion of these entries could have potentially overloaded the EMS (accounting for up to 92,141 additional calls). A similar WBSTS created for the 2009 influenza pandemic was designed with an expert panel and several revisions and was furthermore based on recurrent data in hospitalizations [15].

\section{Development of a chatbot as an addition to the Copenhagen EMS call center}

The perspectives are explicitly to evaluate the effort and further develop an actual active "chatbot" to relieve the EMS of cases with no or mild symptoms and the corona helpline by providing counseling for common questions to improve triage without impeding access for those in need. A "chatbot" is defined as an "artificial intelligence program designed to simulate human conversation via text or speech", as opposed to the current flowchart model [20-21]. The use of chatbots has seen a growing development and usage within the medical literature [21-22], with successful application for recording key symptoms [23-26].

\section{Perspectives and epidemiological surveillance}

The early detection of viral disease outbreaks prior to widespread endemics is necessary to initiate measures to limit the prevalence and mortality [27-29]. Several benefits that can help ease and alleviate the monitoring process by delivering low-cost intuitive and adaptable systems. Web-based systems provide increased transparency and may allow earlier detection of disease outbreaks at a reduced cost [30-31].

\section{Strengths and limitations of the study}

A strength of this study is the large amount of data and the richness of personal information of EMS users in Denmark in general. Another strength of the study is that the speed of the implementation of these emergent initiatives ensured reliable data in the very early phase of the EMS call surge. However, this study has severe limitations, and the data must be interpreted with caution and used for inspiration. In contrast to a randomized trial, this study cannot assume that the callers and users of web-based self-triage would not call or use the WBSTS if these initiatives had not been communicated to the public. If public knowledge of these initiatives did indeed create the observed additional volume by implication of the public awareness of the initiatives, the effect is moderate at best. However, we find that very recent data from the Italian EMS present a situation in which call volume did rise threefold; hence, it is somewhat logical to expect the burden to be "real". Furthermore, the data collected and presented on the WBSTS have several uncertain characteristics, including the inability to portray multiple uses by the same persons and whether users completed the WBSTS.

As such, the conclusions of this study on the effect of caller volume are severely limited by several potentially important uncontrolled factors.

\section{Conclusion}

In the first month of the COVID-19 pandemic in Denmark, the emergency medical dispatch center in Copenhagen was extensively overloaded, resulting in prolonged queue time and thereby limiting access to emergency help and triage for citizens. The Copenhagen EMS developed and implemented a coronavirus hotline and a web-based self-triage system to reduce nonemergency call volume on the emergency medical 
dispatch centers. The introduction of the coronavirus hotline showed reduced call volume and queue time to the EMS 1813 medical helpline. Other EMS systems can implement these emergent measures to enhance capacity and potentially use them as early warning tools to help monitor future epidemics.

\section{Abbreviations}

COVID-19

coronavirus disease 2019

EMDC

emergency medical dispatch center

WBSTS

web-based self-triage system

EMS

emergency medical services

WHO

World Health Organization

\section{Declarations}

\section{Ethics approval and consent to participate}

We followed the General Data Protection Regulation and registered the study with the Danish Data Protection Agency (journal number P-2020-343). The study was approved by the Danish Patient Safety Authority (journal number 31-1521-267). The Research Ethics Committee in the Capital Region of Denmark waived the need for ethical approval (journal number 20026743). All data was aggregated anonymous data and informed consent was not relevant in current study.

\section{Consent for publication}

Not applicable

\section{Availability of data and materials}

Data are available upon reasonable request. Please email the corresponding author to request the relevant data. Please provide the authors of the article with a detailed protocol for the proposed study and supply information about the funding and resources to conduct the study. If appropriate, invite the original author[s] to participate in the re-analysis. If a month elapses without a response from the authors, please email the editorial office.

\section{Competing Interests}

None of the authors has a financial conflict of interest. 
The Copenhagen Emergency Medical Services have received unrestricted research grants from the Laerdal Foundation. The TrygFoundation has supported a large number of projects. The Copenhagen EMS has received a research grant from Novo Nordic Foundation to develop a chatbot based on artificial intelligence computing. None of these occurrences has influenced data collection, data processing, or the analysis or interpretation of data.

\section{Funding}

This study has not received any funding. However, the results of this study is to be used for further development in a linked study supported by the Novo Nordisk Foundation with an unrestricted grant (grant number: NNF20SA0062893).

\section{Author contributions}

All authors agreed on the study setup, data collection and analysis. TJ, the first author, was involved in the data collection and drafted the manuscript along with MGH, MSJ, SNB and HCC. SNB performed all data processing and analysis. All authors were involved in the critical review of the manuscript.

\section{Acknowledgments}

Special thanks to Head of Data, Controlling and IT,MikkelDahlstrømJørgensen, and his data management team at the Copenhagen EMS for ensuring data collection and enabling data analysis.

\section{References}

1. COVID-19: towards controlling of a pandemic [published online ahead of print, 2020 Mar 17] 10.1016/S0140-6736(20)30673-5

Bedford J, Enria D, Giesecke J, et al. COVID-19: towards controlling of a pandemic [published online ahead of print, 2020 Mar 17]. Lancet. 2020;S0140-6736(20)30673-5. doi:10.1016/S0140-6736(20)30673-5.

2. Clancy T, Neuwirth C, Bukowski G. Lessons learned in implementing a $24 / 7$ public health call center in response to H1N1 in the state of New Jersey. Am J Disaster Med. 2009;4(5):253-60.

3. 10.1186/s12940-016-0109-0

Calkins MM, Isaksen TB, Stubbs BA, Yost MG, Fenske RA. Impacts of extreme heat on emergency medical service calls in King County, Washington, 2007-2012: relative risk and time series analyses of basic and advanced life support. Environ Health. 2016;15:13. Published 2016 Jan 28. doi:10.1186/s12940-0160109-0.

4. Andrew E, Nehme Z, Bernard S, et al. Stormy weather: a retrospective analysis of demand for emergency medical services during epidemic thunderstorm asthma. BMJ. 2017;359:j5636. doi:10.1136/bmj.j5636. Published 2017 Dec 13.

5. Vilke GM, Smith AM, Stepanski BM, Ray LU, Murrin PA, Chan TC. Impact of the San Diego county firestorm on emergency medical services. Prehosp Disaster Med. 2006;21(5):353-8. 
doi:10.1017/s1049023x00004003.

\section{10.1097/EDE.0000000000000347}

Brunetti ND, Dellegrottaglie G, De Gennaro L, Gaglione A, Di Biase M. 2014 Failed Influenza Vaccination Winter Campaign: Impact on Emergency Medical Service Calls Assessed by Telemedicine. Epidemiology. 2015;26(5):e61-e62. doi:10.1097/EDE.0000000000000347.

\section{7. $10.1097 /$ EDE.0000000000000347}

Brunetti ND, Dellegrottaglie G, De Gennaro L, Gaglione A, Di Biase M. 2014 Failed Influenza Vaccination Winter Campaign: Impact on Emergency Medical Service Calls Assessed by Telemedicine. Epidemiology. 2015;26(5):e61-e62. doi:10.1097/EDE.0000000000000347.

8. Adhikari BB, Koonin LM, Mugambi ML, et al. Estimating Weekly Call Volume to a National Nurse Telephone Triage Line in an Influenza Pandemic. Health Secur. 2018;16(5):334-40. doi:10.1089/hs.2018.0061.

9. LaRussa P. Pandemic novel 2009 H1N1 influenza: what have we learned? Semin Respir Crit Care Med. 2011;32(4):393-9. doi:10.1055/s-0031-1283279.

10. Semeraro F, Gamberini L, Tartaglione M, et al. An integrated response to the impact of coronavirus outbreak on the Emergency Medical Services of Emilia Romagna [published online ahead of print, 2020 Mar 20]. Resuscitation. 2020;S0300-9572(20):30114-3. doi:10.1016/j.resuscitation.2020.03.005.

11. Danish Serological Institute. 2020. Danish Serological Institute - COVID-19 Surveillance. [ONLINE] Available at: https://www.ssi.dk. [Accessed 14 April 2020].

12. Lindskou TA, Mikkelsen S, Christensen EF, et al. The Danish prehospital emergency healthcare system and research possibilities. Scand J Trauma Resusc Emerg Med. 2019;27(1):100. doi:10.1186/s13049-0190676-5. Published 2019 Nov 4.

13. Koonin LM, Hanfling D. Broadening access to medical care during a severe influenza pandemic: the CDC nurse triage line project. Biosecur Bioterror. 2013;11(1):75-80. doi:10.1089/bsp.2013.0012.

14. Spaulding ABRadi DMacleod Het al. Design and implementation of a statewide influenza nurse triage line in response to pandemic H1N1 influenzaPublic Health Rep20121275532540.17. Spaulding AB Spaulding ABRadi DMacleod Het al. Design and implementation of a statewide influenza nurse triage line in response to pandemic H1N1 influenzaPublic Health Rep20121275532540.17. Spaulding AB. Radi D, Macleod $\mathrm{H}$, et al. Design and implementation of a statewide influenza nurse triage line in response to pandemic H1N1 influenza. Public Health Rep.

15. Kellermann AL, Isakov AP, Parker R, Handrigan MT, Foldy S. Web-based self-triage of influenza-like illness during the 2009 H1N1 influenza pandemic. Ann Emerg Med. 2010;56(3):288-94.e6. doi:10.1016/j.annemergmed.2010.04.005.

16. Anhang Price R, Fagbuyi D, Harris R, et al. Feasibility of web-based self-triage by parents of children with influenza-like illness: a cautionary tale. JAMA Pediatr. 2013;167(2):1-1-2-118.

doi:10.1001/jamapediatrics.2013.1573.

17. Wang D, Hu B, Hu C, et al. Clinical Characteristics of 138 Hospitalized Patients With 2019 Novel Coronavirus-Infected Pneumonia in Wuhan, China [published online ahead of print, 2020 Feb 7]. JAMA. 2020;e201585. doi:10.1001/jama.2020.1585.

18. $10.1001 /$ jama.2020.5394 
Grasselli G, Zangrillo A, Zanella A, et al. Baseline Characteristics and Outcomes of 1591 Patients Infected With SARS-CoV-2 Admitted to ICUs of the Lombardy Region, Italy [published online ahead of print, 2020 Apr 6]. JAMA. 2020;e205394. doi:10.1001/jama.2020.5394.

19. Heather $L, O$ 'Brien $P$, Cairns $M$, Hall. A practical approach to measuring user engagement with the refined user engagement scale (UES) and new UES short form, International Journal of Human-Computer Studies, Volume 1-1-2, 2018, Pages 28-39, ISSN 1071-5819, https://doi.org/10.1016/j.ijhcs.2018.01.004.

20. Abd-Alrazaq AA, Alajlani M, Alalwan AA, Bewick BM, Gardner P, Househ M. An overview of the features of chatbots in mental health: A scoping review. Int J Med Inform. 2019;132:103978. doi:10.1016/j.jijmedinf.2019.103978.

21. Palanica A, Flaschner P, Thommandram A, Li M, Fossat Y. Physicians' Perceptions of Chatbots in Health Care: Cross-Sectional Web-Based Survey. J Med Internet Res. 2019;21(4):e12887. doi:10.2196/12887. Published 2019 Apr 5.

22. Ghosh S, Bhatia S, Bhatia A. Quro: Facilitating User Symptom Check Using a Personalised ChatbotOriented Dialogue System. Stud Health Technol Inform. 2018;252:51-6.

23. Chetlen A, Artrip R, Drury B, Arbaiza A, Moore M. Novel Use of Chatbot Technology to Educate Patients Before Breast Biopsy. J Am Coll Radiol. 2019;16(9 Pt B):1305-8. doi:10.1016/j.jacr.2019.05.050.

24. Pereira J, Díaz Ó. Using Health Chatbots for Behavior Change: A Mapping Study. J Med Syst. 2019;43(5):135. doi:10.1007/s10916-019-1237-1. Published 2019 Apr 4.

25. Denecke K, Hochreutener SL, Pöpel A, May R. Self-Anamnesis with a Conversational User Interface: Concept and Usability Study. Methods Inf Med. 2018;57(5-06):243-52. doi:10.1055/s-0038-1675822.

26. Reiswich A, Haag M. Evaluation of Chatbot Prototypes for Taking the Virtual Patient's History. Stud Health Technol Inform. 2019;260:73-80.

27. Heymann D, editor. Control of Communicable Diseases Manual. Washington, American Public Health Association. 2015.

28. Jefferson T, Del Mar CB, Dooley L, et al. Physical interventions to interrupt or reduce the spread of respiratory viruses. Cochrane Database Syst Rev. 2011;2011(7):CD 006207.

doi:10.1002/14651858.CD 006207.pub4. Published 2011 Jul 6.

29. Choi J, Cho Y, Shim E, Woo H. Web-based infectious disease surveillance systems and public health perspectives: a systematic review. BMC Public Health. 2016;16(1):1238. doi:10.1186/s12889-016-3893-0. Published 2016 Dec 8.

30. Wilson K, Brownstein JS. Early detection of disease outbreaks using the Internet. CMAJ. 2009;180(8):829-31. doi:10.1503/cmaj.090215.

31. Ginsberg J, Mohebbi MH, Patel RS, Brammer L, Smolinski MS, Brilliant L. Detecting influenza epidemics using search engine query data. Nature. 2009;457(7232):1012-4. doi:10.1038/nature07634.

\section{Figures}


Figare L. Flowchart for the corronavirus hotine

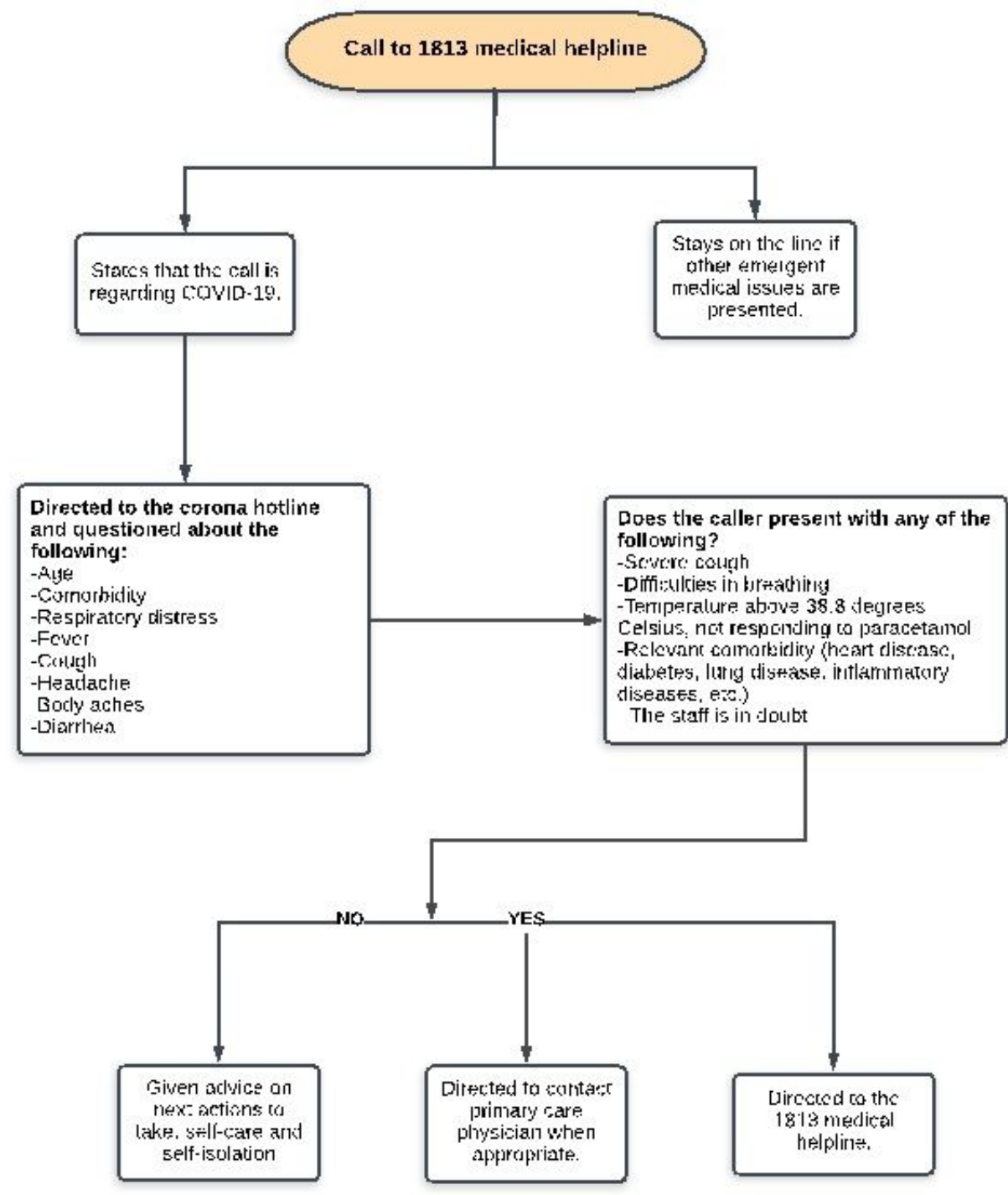

Figure 1

Flowchart for the coronavirus hotline 


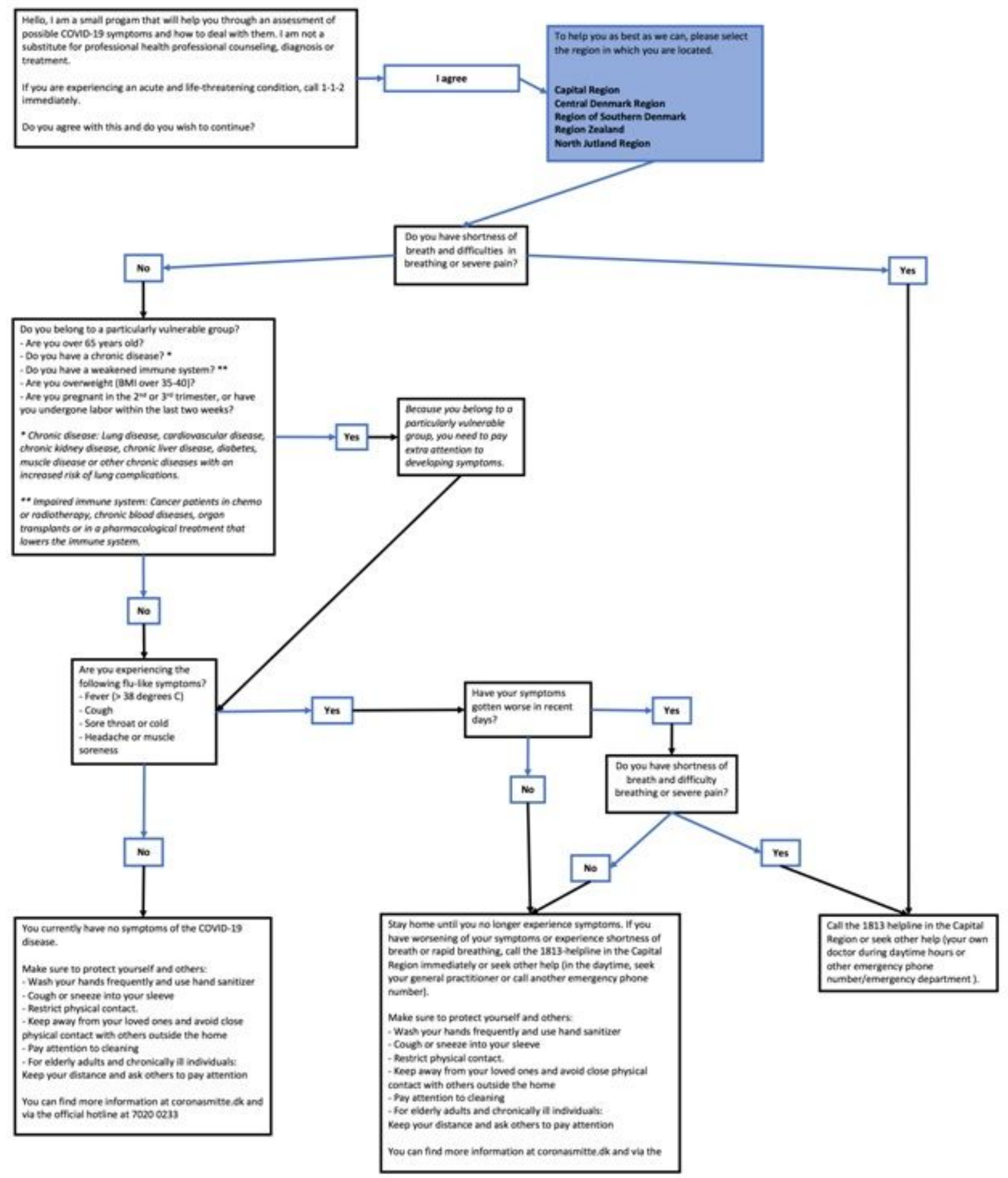

Figure 2

Flowchart for the initial web-based self-triage system 


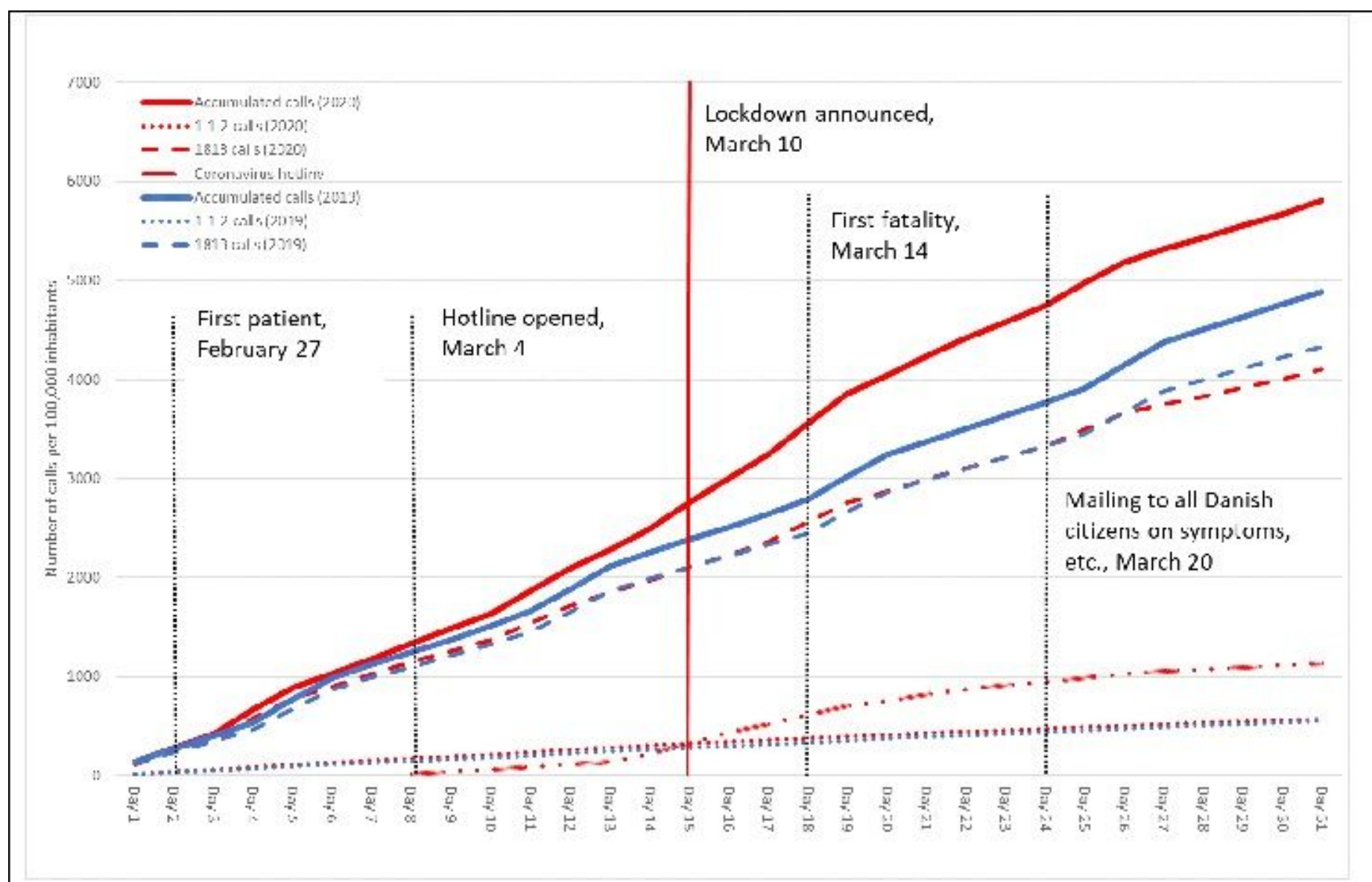

Call volume [number of calls] for the 1813 medical helpline, the 1-1-2 emergency line and the COVID helpline from February 26 to March 27, displayed for 2020 and 2019.

\section{Figure 3}

Accumulated call volumes and web-based self-triage system use 


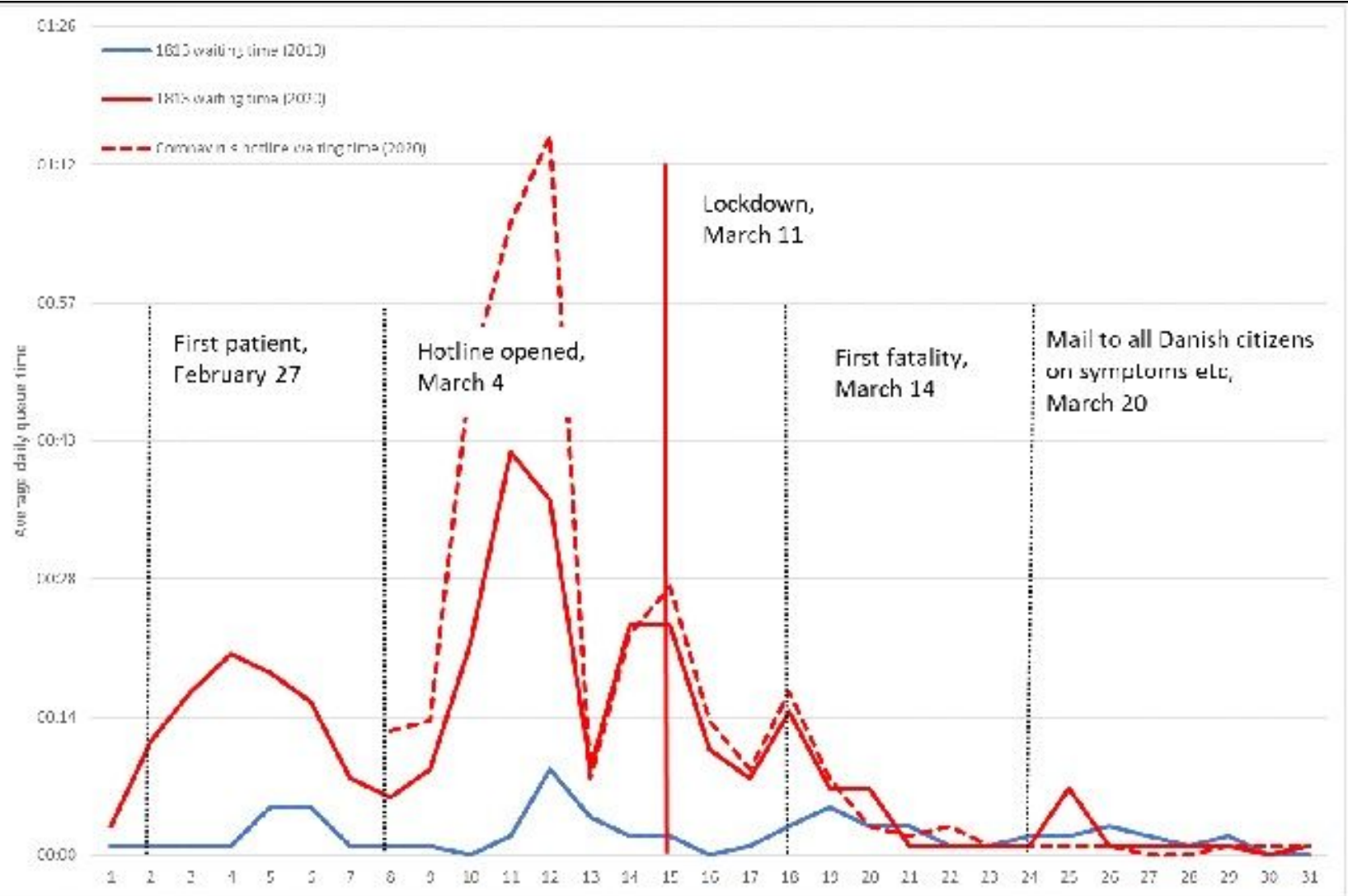

Day 1: February 26 in both 2019 and 2020. 2020 was a leap year, and hence, comparable dates cannot be displayed for both years. The first COVID-19 patient was confirmed on February 27, 2020. The coronavirus hotline was initiated on the March 4, 2020. The lockdown of Denmark was announced on March 11 and initiated on March 13. The first fatality due to COVID-19 was confirmed on March 14, 2020. An official mailing with a description of symptoms was sent to all Danish citizens on March 20,2020.

\section{Figure 4}

Queues for EMS lines and key events around the Danish COVID-19 impact 